\title{
Garimpo e mercúrio: impactos ambientais e saúde humana
}

\author{
Victor Gomes de-Paula* \\ Ronald Lamas-Corrêa \\ Valdi Lopes Tutunji ${ }^{* * *}$
}

\begin{abstract}
RESUMO - A poluição provocada pelo mercúrio é um problema mundial relacionado às atividades de garimpo, com profundos impactos na saúde humana e no meio ambiente. Recentes avanços têm demonstrado uma relação causal entre a exposição ao mercúrio e diversas patologias humanas. O objetivo deste trabalho é discutir os efeitos do mercúrio como agente etiológico de patologias com base na literatura recente. A irreversibilidade dos danos ocasionados pela intoxicação por metais pesados alerta para a necessidade do segmento continuado e permanente destas populações. $O$ desenvolvimento de novas metodologias, que permitam estabelecer uma relação causal, entre a intoxicação por metais pesados e o quadro epidemiológico presente na população exposta, deve ser implementado, estabelecendo as bases para avaliar a capacidade de resolução das medidas preventivas, corretivas e/ou mitigadoras.
\end{abstract}

Palavras-chave: mercúrio, garimpo, saúde humana.

\section{Mining and mercury: environmental impacts and human health}

\begin{abstract}
The mercurial pollution is a worldwide problem related to gold mining activities with deep impacts on human and environmental health. Early advances have been showed a causal effect between mercury exposure and several human diseases. The objective of this paper is to discuss the effects of mercury as etiologic agent in several pathologies, based on recent literature data. The damage related to heavy metals intoxication alerts for the need of continuous monitoring of this kind of exposure. The development of new methodologies should be implemented searching the creation of a new background to evaluate the efficacy of preventive and corrective actions.
\end{abstract}

Keywords: mercury, mining, human health.

\footnotetext{
* Graduando em Biomedicina - UniCEUB

Biólogo, MBA em Política e Gestão em Sistemas de Saúde - FGV, MBA em Avaliação de Impacto Ambiental - UPIS, Professor de Epidemiologia e Administração em Saúde - UniCEUB

*** Biólogo, Pós-graduado em Saúde Pública - ENSP/ FIOCRUZ, Mestrando em Nutrição Humana UnB, Professor de Análises Ambientais - UniCEUB. biomedicina@ uniceub.com.br
} 


\section{Introdução}

A poluição mercurial, decorrente da atividade garimpeira, tem sido objeto de estudos no Brasil e no mundo. A atividade extrativa mineral altera o meio ambiente, tornando-se fonte de degradação, quando empreendida sem as medidas de controle adequadas.

O mercúrio metálico lançado no meio ambiente, é volátil, podendo ser oxidado e metilado para a forma mais tóxica, o metil-mercúrio, incorporando-se aos organismos vivos pela cadeia alimentar. Dessa forma, pode ocasionar sérios danos à saúde dos animais e do ser humano (TANNÚS, 2001).

O objetivo do presente trabalho é realizar uma revisão bibliográfica sobre os impactos à saúde humana decorrentes da utilização do mercúrio na atividade garimpeira. Estudos dessa natureza podem ajudar a compreender as relações entre meio ambiente e saúde pública, possibilitando o desenvolvimento de novas propostas de controle e remediação ambiental.

\section{Garimpo e mercúrio}

A poluição por mercúrio é comum em áreas de garimpo, afetando vastas regiões do Brasil. Os garimpeiros usam mercúrio para coletar o ouro dos concentrados na forma de um amálgama e recuperam o ouro metálico "queimando-o", volatilizando o mercúrio, o qual é levado pelo vento e logo se precipita (SCARPELLI, 2003). Pelo desconhecimento técnico-operacional desse processo e pela ausência da cultura para reciclagem do mercúrio aliadas ao custo relativamente baixo do metal líquido, grandes quantidades de mercúrio têm sido lançadas no solo, na água e no ar.

O garimpo de ouro, além de acarretar problemas, como a descaracterização da morfologia original do terreno, a supressão da vegetação e o assoreamento dos cursos d'água, pode gerar rejeitos contendo mercúrio metálico (TANNÚS, 2001). O mau uso da terra também pode aumentar os níveis de metilação do mercúrio. A erosão pode transportar o mercúrio para corpos d'água locais e contaminar o lençol freático (HIMENES et al., 2005). Fatores, tais como, pH, condutividade elétrica, disponibilidade de oxigênio, temperatura, atividade biológica e concentração de nutrientes, entre outros, 
são relevantes nos processos de organificação do mercúrio e outros metais pesados no solo e na água (FAGERSTROM et al., 1972; BOISCHIO, 1993).

O uso de mercúrio pelos garimpeiros para concentração do ouro na bateia justifica a necessidade de estudos adequados sobre esse processo e para descontaminação de áreas poluídas por esse metal. Diversos métodos têm sido desenvolvidos para a remoção de mercúrio de efluentes industriais e de rejeitos do processo de amalgamação. Em geral, os tratamentos envolvem técnicas físico-químicas, como separação por decantação, precipitação química, coagulação, absorção, troca iônica e extração por solvente, eletro-oxidação e flotação. Também estão sendo avaliados métodos biológicos para o tratamento hidrometalúrgico, a biolixiviação do concentrado mineral, e para o monitoramento, a remoção e a recuperação por bioabsorção de metais contidos em efluentes líquidos (HIMENES et al., 2005).

Estudos recentes realizados no Córrego Rico, município de Paracatu/MG, Brasil, revelaram áreas degradadas pelo garimpo, demonstrando a ictiofauna com traços de metilmercúrio e expressiva quantidade deste metal nos sedimentos, decorrente do último ciclo garimpeiro durante a década de 80. Nessa ocasião, um contingente estimado de 5000 homens empreendeu intenso trabalho, utilizando equipamentos, como bombas de sucção, calhas de concentração, moinhos de martelo. Nesse períoso, o mercúrio foi usado indiscriminadamente.

Diversos estudos têm revelado que, nas áreas onde há maiores índices de contaminação, os níveis de metilmercúrio encontrados variam de $850 \mathrm{ng} / \mathrm{g}$ até 1360 ng/g, quantidade acima do limite máximo de 1000 ng/g estabelecido pelo USFDA (Agência de Drogas e Alimentos dos Estados Unidos) e pelo Ministério da Saúde do Brasil. Da mesma forma, os níveis de mercúrio nas águas do Córrego Rico revelaram valores entre 300 e 3800 ng/L (TANNÚS, 2001).

\section{Mineração em escala industrial}

A mineração em escala industrial é uma atividade que tem gerado controvérsia quanto ao impacto no meio ambiente, na sociedade e na economia dos países em desenvolvimento. A atividade mineradora e a disposição de seus rejeitos têm sido consideradas, há muito tempo, como importantes fontes de degradação ambiental. 
Diante deste quadro, grande esforço tem sido implementado por parte da sociedade, dos governos e das mineradoras, visando minimizar o problema.

Os rejeitos tóxicos, relacionados à atividade de mineração, têm causado sérios impactos no meio ambiente em todo o mundo. No entanto, esses dados devem vir acompanhados de análises da relação custo/benefício desta importante atividade geradora de empregos e de recursos, a fim de otimizar a relação.

A dificuldade de generalização sobre a toxicidade dos rejeitos da mineração decorre da ampla variação dos seus efeitos. Estes rejeitos contêm grandes quantidades de metais pesados e outros compostos (PEARCE, 2000).

\section{Mercúrio e saúde humana}

\section{Toxicocinética do mercúrio em humanos}

A população pode se expor aos compostos mercuriais pela inalação do ar, pelo consumo de alimentos e água ou pela exposição por contato com a pele. Também tem sido relatada a contaminação por meio de amálgamas dentários (PAVLOGEORGATOS et al., 2002)

A absorção do vapor de mercúrio metálico dá-se principalmente por via pulmonar, através da inalação. A percentagem de retenção nos pulmões varia de $74 \%$ a $76 \%$ à concentração ambiental de $100 \mathrm{mg} / \mathrm{m}^{3}$ (ZAVARIZ; GLINA, 1992). Dos pulmões o mercúrio é levado pelo sangue e distribui-se no organismo, acumulando-se nos rins, no sistema nervoso central, no fígado, na medula óssea, nas vias aéreas superiores, na parede intestinal, na pele, nas glândulas salivares, no coração, nos músculos e na placenta com ampla variedade de efeitos descritos na literatura, conforme pode ser observado na tabela 1 (ZAVARIZ; GLINA, 1992; PAVLOGEORGATOS, 2002). Essa distribuição do metal no organismo pode segundo vários estudos relatados por Pavlogeorgatos (2002), gerar uma ampla variedade de efeitos tais como: doenças autoimunes, imunosupressão, anomalias cromossômicas, leucemia, câncer de fígado e de pulmão, infertilidade masculina, morte fetal, malformações congênitas, redução no peso do cérebro, retardo no crescimento, na fala, no caminar e no desenvolvimento 
intelectual, deficiencia de concentração, insanidade, distúrbios visuais e cegueira, alucinações, tremores, fraqueza muscular, ataxia, paralisia, coma, depressão, dispnéia, hipertensão, taquicardia, perda de audição, de memoria e da sensibilidade ao toque, gastroenterite, pneumonia e morte.

\section{Patogênese da intoxicação por mercúrio}

A toxicidade do mercúrio é derivada da sua capacidade de interferir em reações metabólicas enzimáticas (WHO, 1989; WHO, 1990; KOUIMTZIS, 1994; ATSDR, 1999). Os efeitos do mercúrio no organismo manifestam-se sob a forma de quadro agudo, quando inalado em grande quantidade, no qual podem ocorrer lesões pulmonares, renais, do sistema nervoso central, podendo ocasionar a morte.

A intoxicação crônica afeta o aparelho gastrintestinal e o sistema nervoso, podendo ocasionar distúrbios comportamentais, cujas alterações variam de quadros leves a muito graves. O quadro gastrintestinal manifesta-se por lesões orais, de estômago, intestino e fígado. A gengivite é o distúrbio mais comumente encontrado. Também ocorrem queixas de desagradável gosto amargo ou metálico na boca, sialorréia, ulcerações orais e amolecimento de dentes. Faringite inespecífica é comum. Outra manifestação encontrada é a gastrite e a gastroduodenite (ZAVARIZ; GLINA, 1992).

O quadro neurológico pode manifestar-se por tremores, alterações de sensibilidade dolorosa, térmica e tátil, alteração de reflexos, coordenação motora e até parkinsonismo. O quadro psíquico também pode constituir-se por uma variedade de outras anormalidades como alterações da personalidade, denominada eretismo psíquico, com sinais típicos e precoces da intoxicação crônica por mercúrio, tais como, irritabilidade, alteração da sociabilidade, insônia, estado de ansiedade, timidez, labilidade emocional, e, e nos casos mais graves, ocorre à diminuição da atenção, memória, até um processo de despersonalização geral (ZAVARIZ; GLINA, 1992).

O risco de exposição a agentes químicos inicia-se ainda na vida intra-uterina (período de desenvolvimento fetal). Além de fármacos, agentes químicos lipofílicos, como hidrocarbonetos policíclicos aromáticos (PAH), presentes na fumaça do cigarro, compostos mercuriais orgânicos, como o metilmercúrio e o álcool etílico atravessam 
com facilidade a placenta. A preocupação com a população feminina em idade reprodutiva é grande, pois os organomercuriais ultrapassam a barreira placentária e podem gerar danos como: microcefalia, hiperreflexia, deficiência visual, auditiva, mental e motora, ocasionando impactos adversos sobre a inteligência e desempenho reduzido na área escolar (HIMENES et al., 2005). Os níveis mínimos de exposição intra-uterina causadores de efeitos adversos em crianças são ainda pouco conclusivos (MCKEOWN-EYSSEN et al, 1983). Esses efeitos intra-uterinos geralmente diferem daqueles observados em crianças e adultos (HARADA, 1968; TAKEUSHI, 1968; TOKUOMI, 1968).

A exposição ao metilmercúrio apresenta amplo padrão de alterações no sistema nervoso central, desde o seu desenvolvimento e organização durante o período pré-natal até efeitos relativamente circunscritos, observados durante a vida adulta (CHOI et. al.,1978; HAMADA et. al., 1993; FAUSTMAN et. al., 2002).

Estudos recentes, realizados nas Ilhas Seychelles, Oceano Índico, e nas Ilhas Faroe, no Atlântico Norte, com crianças cujas mães ingeriram peixes contaminados na gestação, apresentaram resultados controversos. Enquanto no primeiro caso, nas Ilhas Seychelles, não houve relação entre os níveis de mercúrio medidos nas mães e o desenvolvimento cognitivo dos conceptos, nas Ilhas Faroe, houve associação entre os níveis de mercúrio medidos no cordão umbilical ao nascimento (média de 22,9 $\mu \mathrm{g} / \mathrm{l}$ ) e o baixo desempenho cognitivo aos 8 anos de vida.

Outras pesquisas têm demonstrado que a deficiência em testes psicológicos, manifestada por crianças aos 6 anos de idade pode estar associada à exposição ao mercúrio, com níveis de 13 a 15 ppm no cabelo materno, durante a gravidez (KJELLSTROM et. al., 1989).

Áreas geográficas definidas para pesquisa permitem estabelecer parâmetros de normalidade regional, que possam servir de base para análises comparativas posteriores, sejam por dosagens diretas em materiais biológicos, seja por análise estatística da prevalência de patologias relacionadas à intoxicação por mercúrio (SANTOS FILHO, 1993; KINJO, 1996; SANTOS et. al., 2003).

As populações em risco de intoxicação por mercúrio através das vias respiratórias e alimentar constituem grupos de investigação, como, por exemplo, as 
populações ribeirinhas que utilizam o pescado como lazer ou fonte alternativa de proteínas (BOSCHIO; BARBOSA, 1993).

\section{Mercúrio e carcinogênese}

A literatura sugere também, que a exposição ambiental e ou ocupacional ao mercúrio e a outros metais pesados pode agir como fator desencadeante de formas de neoplasias, por modificação de proteínas, peroxidação de lipídeos e danos ao DNA (CHEN, 2001).

Primariamente, a pele atua como barreira entre o meio ambiente e o organismo e está exposta a uma série de agentes tóxicos, inclusive a metais pesados. Numerosos estudos têm demonstrado a atividade carcinogênica dos metais sobre a pele humana (BAUDOUIN et. al., 2002).

A correlação entre o uso de fungicidas mercuriais e a ocorrência de leucemia entre habitantes de áreas rurais foi relatada na literatura. Este achado foi corroborado pela elevada frequiência de leucemia linfocítica em gado bovino alimentado com rações contaminadas com estes agrotóxicos (JANICKI, 1987).

As relações entre mercúrio e outros metais pesados com diversas formas de câncer têm-se tornado uma preocupação. Há evidências disso para neoplasias de pele, como já mencionado, pulmão, fígado, rim, baço, cavidade nasal, medula óssea, laringe, intestino e estômago (RATNAIKE, 2003).

\section{Considerações Finais}

Tendo em vista a gravidade da intoxicação por mercúrio e o fato de que, no ambiente, ocorre exposição combinada e simultânea a outros fatores de risco, deve-se considerar que as populações expostas ao mercúrio em áreas de garimpo e mineração de escala industrial necessitam de ajuda, e podem ser voluntários de profundas investigações científicas.

A irreversibilidade dos danos ocasionados pela intoxicação por metais pesados alerta para a necessidade de vigilância continuada e permanente destas populações. $\mathrm{O}$ desenvolvimento de novas metodologias que permitam estabelecer relação causal entre 
a intoxicação por metais pesados e o quadro epidemiológico presente na população exposta deve ser implementado, estabelecendo as bases para avaliar a resolutividade das medidas preventivas, corretivas e ou mitigadoras.

\section{Referências}

ATSDR (AGENCY FOR TOXIC SUBSTANCES \& DISEASE REGISTRY). Public health statement for mercury. 1999. Disponível em: http://www.atsdr.cdc.gov/toxprofiles/phs46.html. Acesso em 13 out. 2005.

BAUDOUIN, C. et. al.. Environmental pollutants and skin cancer. Cell Biology and Toxicology, Netherlands, v. 18, n. 5, p. 341-348. 2002.

BOISCHIO, A. A. P.; BARBOSA, A. . Exposição ao Mercúrio orgânico em populações ribeirinhas do Alto Madeira, Rondônia, 1991: Resultados Preliminares. Cadernos de Saúde Pública, Rio de Janeiro, v. 9, n. 2, p. 155-160. 1993.

CHEN, F. et. al. Cell apoptosis induced by carcinogenic metals. Molecular and Cellular Biochemistry, Netherlands, v. 222, n. 1-2, p. 183-188. 2001.

CHOI, B. H. et. al. Abnormal neuronal migration, deranged cerebral cortical organization and diffuse white matter astrocytosis of human fetal brain: major effect of methylmercury poisoning in utero. Journal of Neuropathology \& Experimental Neurology, United States, v. 37, v. 6, p. 719-733, 1978.

FAGERSTROM, T.; JERNELOV, A. Some aspects of the quantitative ecology of mercury. Water Research, London, v. 6, p.1193-1202. 1972.

FAUSTMAN, E. M. et. al. Investigations of methylmercury-induced alterations in neurogenesis. Environmental Health Perspectives, United States, v. 110, n. 5, p. 859864. 2002.

HAMADA, R. et. al. Computed tomography in fetal methylmercury poisoing. Journal of Toxicology: Clinical Toxicology, United States, v. 31, n. 1, p. 101-106. 1993.

HARADA, Y. Clinical investigations on minamata disease. C. Congenital (or fetal) Minamata disease. In: STUDY GROUP OF MINAMATA DISEASE (Eds.) Minamata disease. Japan: Kumamoto University, p. 73-91. 1968.

HIMENES, G. F.; TUTUNJI, V. L. Escherichia coli e Pseudomonas aeruginosa resistentes ao mercúrio: bioindicadores de contaminação mercurial em ambientes aquáticos. Monografia (graduação) Curso de Biologia: Centro Universitário de Brasília, 2005. 
JANICKI, K.; DROBOWOLSKI, J.; KRASNICKI, K. Correlation between contamination of the rural environment with mercury and occurrence of leukaemia in men and cattle. Chemosphere, Netherlands, v. 16, n.1, p. 252-257. 1987.

KINJO, Y. et. Al. Cancer mortality in Minamata disease patients exposes to methylmercury through fish diet. Journal of Epidemiology, v. 6, n. 3, p.134-138. 1996. KJELlSTROM, T. et. al. Physical and mental development of children with prenatal exposure to mercury from fish. Stage II: interviews and psychological tests at age 6. Report 3642. Sweden: National Swedish Environmental Protection Board. 1989.

KOUIMTZIS, T. Environmental chemistry. Greece: Ziti Publishers, 1994.

McKEOWN-EYSSEN, G. E.; RUEDY, J. Prevalence of neurological abnormality in Cree Indian exposed to methylmercury in Northern Quebec. Clinical \& Investigative Medicine, Canada, v. 6, p. 161-169. 1983

PAVLOGEORGATOS, G.; KIKILIAS, V. The Importance of Mercury Determination and Speciation to the Health of the General Population. Global Nest: The International Journal, Greece, v. 4, n. 2-3, p. 107-125. 2002.

PEARCE, F. Tails of Woe. 2000. Disponível em: http://users.nlc.net.au/mpi/std/std_newscientist_print.html. Acesso em 13 out. 2005.

RATNAIKE, R. N. Acute and chronic arsenic toxicity. Postgraduate Medical Journal, United Kingdom, v. 79, p. 391-396. 2003.

SANTOS, E. C. O. et al. Exposição ao Mercúrio e ao Arsênio em Estados da Amazônia: Síntese dos estudos do Instituto Evandro Chagas/FUNASA. Revista Brasileira de Epidemiologia, v. 6, n. 2, p.171-185. 2003.

SANTOS FILHO, E. et. al. Teores de Chumbo e Mercúrio em cabelo de crianças residentes em Cubatão, na Região Sudeste do Brasil. Revista de Saúde Pública, São Paulo, v. 27, n. 2, p. 81-86, 1993.

SCARPELLI, W. Introdução à geologia médica. São Paulo: USP, 2003.

TANNÚS, M. B. et. al.. Projeto Paracatu: concepção e resultados preliminares. Jornada Internacional sobre el Impacto Ambiental del Mercúrio Utilizado por la Mineria Aurífera Artesanal em Iberoamérica. Setembro de 2001. Lima, Peru: CYTED, 2001.

TAKEUSHI, T. Pathology of Minamata disease. In: STUDY GROUP OF MINAMATA DISEASE (Eds.). Minamata Disease. Japan: Kumamoto University, p.141-228. 1968.

TOKUOMI, H. Clinical Investigations on Minamata Disease. Minamata - Disease in Human Adult. In: STUDY GROUP OF MINAMATA DISEASE (Eds.). Minamata Disease. Japan: Kumamoto University, 37-72. 1968. 
WHO (WORLD HEALTH ORGANIZATION). Mercury - Environmental Aspects. Environmental Health Criteria 86, Geneva: WHO, 1989.

Methylmercury. Environmental Health Criteria 101, Geneva: WHO, 1990.

ZAVARIZ, C.; GLINA, D. M. R. Avaliação clínico - neuro - psicológica de trabalhadores expostos a mercúrio metálico em indústria de lâmpadas elétricas. Revista de Saúde Pública, São Paulo, v. 26, n. 5, p. 356-365. 1992. 